\title{
Journée des délégués tarifaires de la FMH - entre mythe et réalité
}

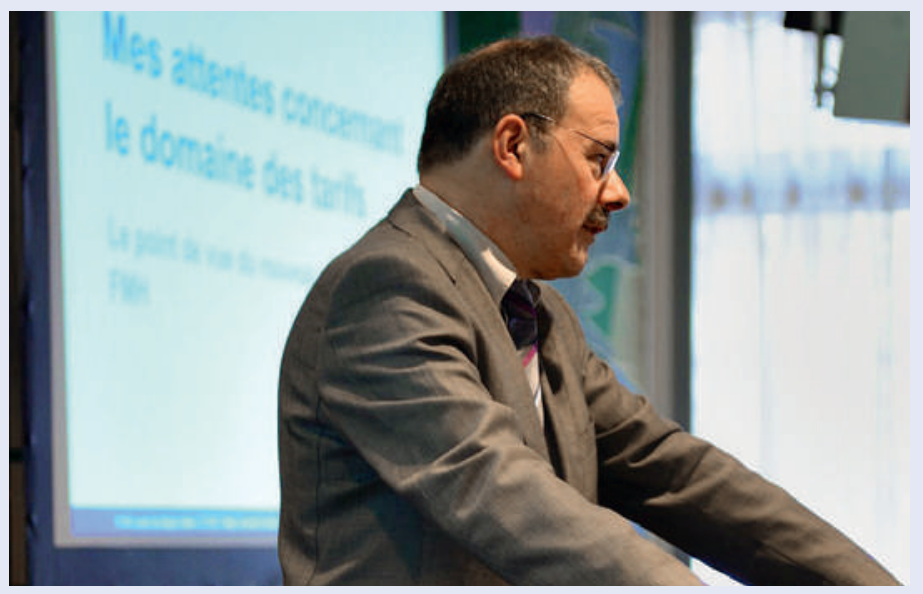

La rencontre d'automne des délégués tarifaires organisée par le domaine Tarifs et conventions pour la médecine ambulatoire en Suisse a de nouveau connu un vif succès. Les délégués tarifaires des sociétés de discipline médicale et les délégués tarifaires cantonaux ont ainsi pu s'informer des derniers développements dans le domaine des tarifs ambulatoires et profiter de cette journée pour échanger. Le Dr Jürg Schlup, président élu de la FMH, a accueilli les participants par un bref discours d'introduction.

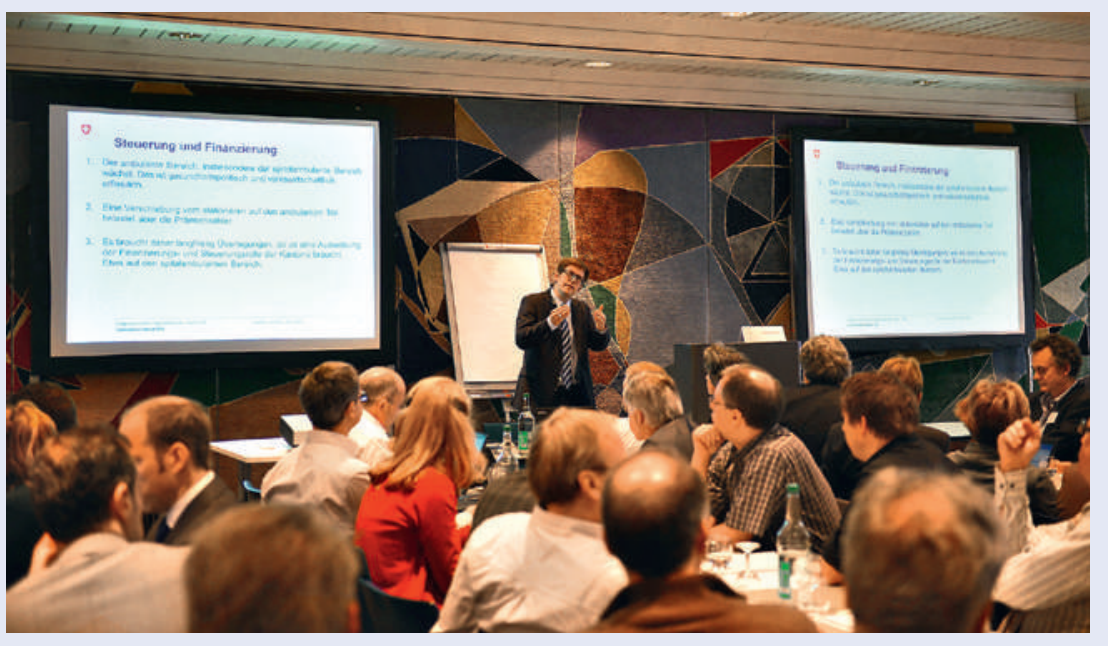

Dans son exposé, Thomas Christen, licencié en droit et collaborateur personnel du Conseiller fédéral Alain Berset, a donné un aperçu détaillé des sujets de politique de santé actuellement traités par le Conseil fédéral. La discussion qui s'ensuivit a montré le large éventail de questions et de tâches dont nos hautes instances politiques doivent s'occuper, ce qu'elles ne manquent d'ailleurs pas de faire.

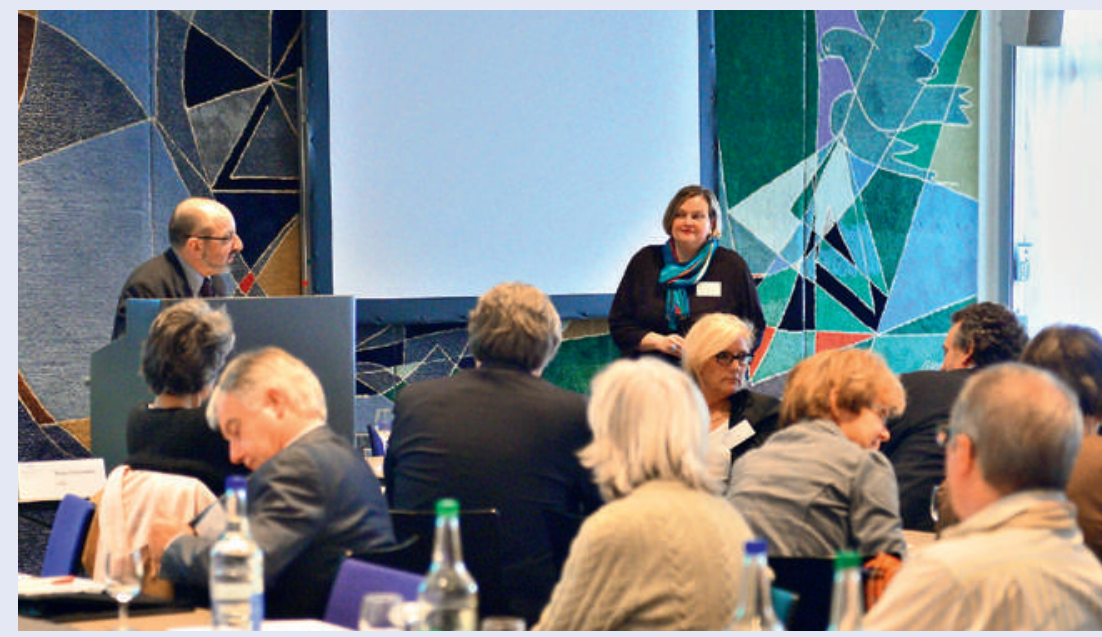

A l'heure actuelle, il n'est pas simple de connaître et de garder une vue d'ensemble de toutes les discussions et négociations en cours dans le domaine des tarifs. Le Dr Ernst Gähler, vice-président de la FMH et responsable du domaine Tarifs et conventions pour la médecine ambulatoire, a pris position sur les nombreux mythes qui circulent. Pour cela, il s'est basé sur des faits et des situations concrètes. 


\section{Exposés et ateliers}

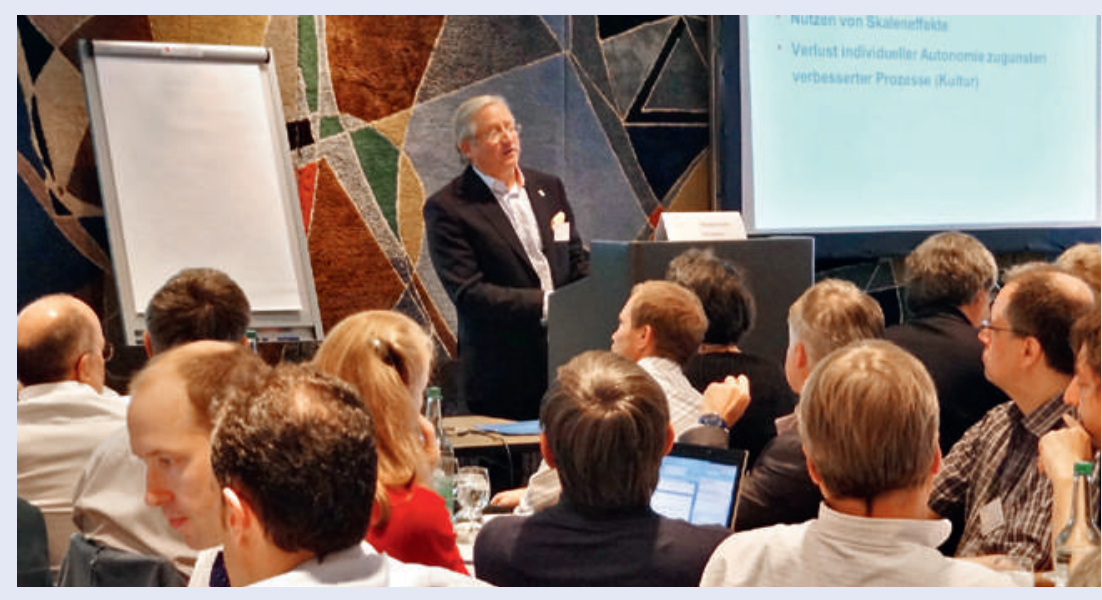

Le Prof. Thomas Szucs, président du Conseil d'administration d'Helsana, a présenté la voie que les assureurs souhaitent suivre dans un avenir proche. Selon lui, il est clair que le secteur de la santé ne pourra se développer de manière optimale que si les différents partenaires tarifaires négocient et mettent en œuvre leurs décisions dans un esprit de coopération.

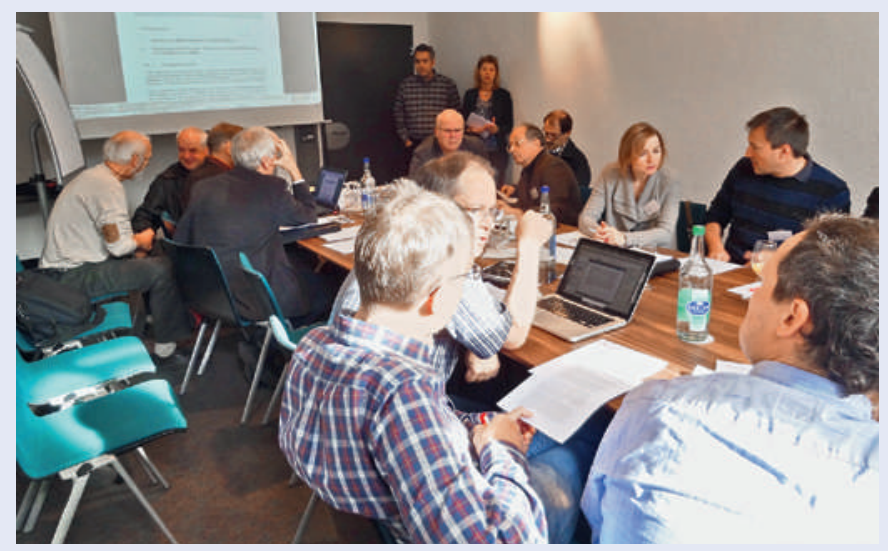

Les trois ateliers proposés dans la matinée ont été l'occasion de nombreux calculs et simulations, ils ont incité la discussion et aussi permis d'émettre des critiques. Bien qu'il soit en place depuis bientôt huit ans, le TARMED suscite encore et toujours des discussions animées. Parfois, les négociations tarifaires peuvent laisser perplexes.

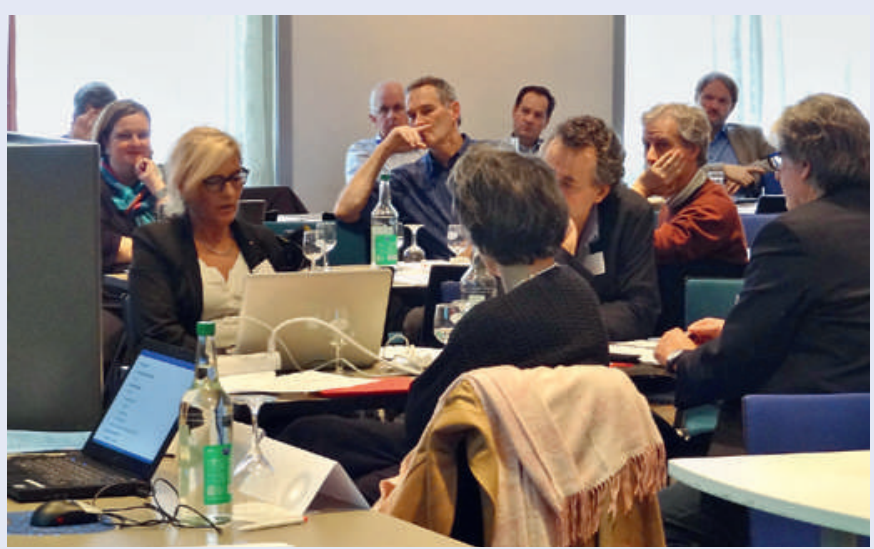

En effet, il n'est pas uniquement question de la révision du TARMED qui n'a fait l'objet d'aucune mise à jour ni d'aucun bilan depuis son introduction, mais il s'agit également de réévaluer et éventuellement d'adapter les organisations et le déroulement de leurs processus (TARMEDSuisse, CPP etc.).

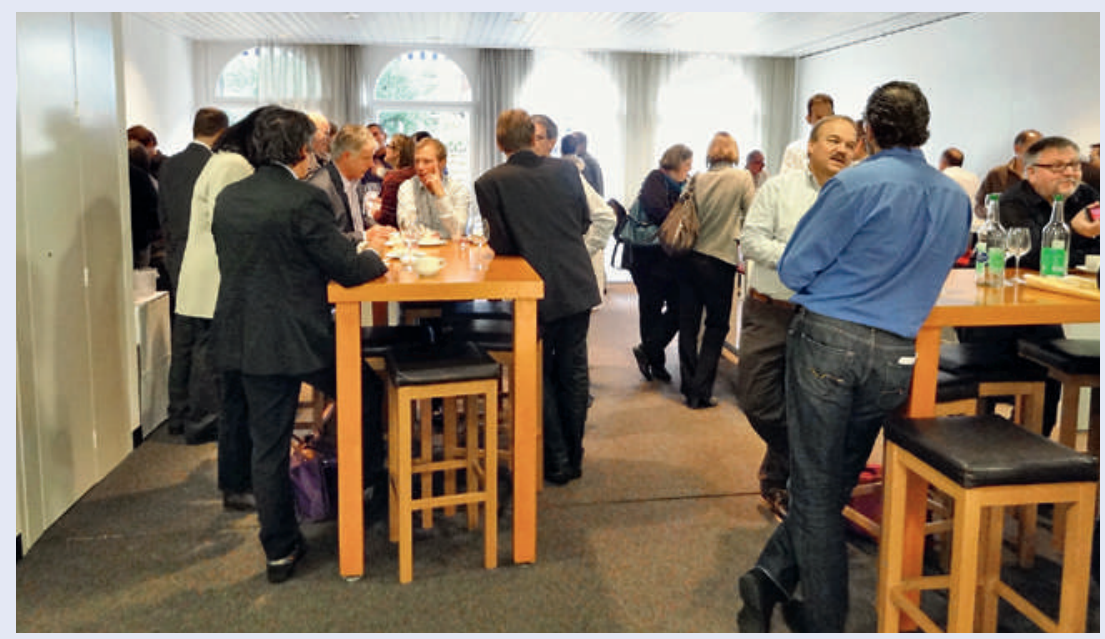

Les délégués tarifaires des différentes sociétés de discipline ont également mis à profit les pauses, le repas de midi et l'apéritif en fin de rencontre pour nouer de nouveaux contacts entre eux ou les consolider.

Vous trouverez tous les exposés et documents présentés lors de cette journée sur notre site internet sous FMH $\rightarrow$ TARMED $\rightarrow$ Actuel

La prochaine rencontre des délégués tarifaires aura lieu le mercredi 20 mars 2013 à l'Hôtel Ador à Berne.

Correspondance: FMH, Tarifs et conventions pour la médecine ambulatoire en Suisse, Froburgstrasse 15, CH-4600 Olten, tél. 031359 w12 30 ou tarife. ambulant[at]fmh.ch 